\title{
Research on Application of Manuscript Management System of Journals
}

\author{
Lihua Zhao \\ Editorial Department of Journal of Jilin Agricultural University, Changchun 130118, China \\ Zhaolihua2004@126.com
}

\begin{abstract}
Keywords: Manuscript management system; Editing and publishing process; Journal; Author; Reviewer expert; Editor
\end{abstract}

\begin{abstract}
The traditional editing and publishing model has become a serious problem restricting the development of journals. Manuscript management system based on the Internet platform has become a necessary software application system in the course of journal development. More and more editorial departments have used the system because it can deliver real-time information between authors, reviewers, the editorial board, editors in chief, editors and readers, relieve the burden of editors, increase the work efficiency of editors, shorten the publishing cycle and attract excellent manuscripts etc. This paper introduces the composition and functions of the manuscript management system (Ver2.0), summarizes the application advantages of the system, discloses some problems in applying the system and puts forward some suggestions.
\end{abstract}

\section{Introduction}

With the popularization and development of computer and network technology, sci-tech journals have the basic condition to realize the network management of editing process[1,2]. The traditional editing and publishing model has become a serious problem restricting the development of journals. Therefore, the editorial office automation, the journal publication digitization and the network practical application are more and more recognized and accepted by the journal editorial departments. The manuscript management system based on the Internet platform is a new achievement of software development in recent years [3]. It has become a necessary software application system in the course of journal development. More and more editorial departments have used the system because it can deliver real-time information between authors, reviewers, the editorial board, editors in chief, editors and readers, relieve the burden of editors, increase the work efficiency of editors, shorten the publishing cycle and attract excellent manuscripts etc.[2-7]. In order to strengthen the management of journal manuscripts, optimize the process of manuscript management and improve the efficiency of editing and publishing, in 2006 the editorial department of Journal of Jilin Agricultural University started using the manuscript management system developed and designed by Beijing Magtech Science and Technology Development Co. Ltd. (Ver2.0).In applying the system, the author of this article has some personal experiences. From the initial lack of adaption to the current skilled application, from the discovery of problems to the solution. After years of practice, some experiences have been explored. Of course, there are still some problems in the application, which need to be solved. This paper analyzes the practice of applying the manuscript management system in editorial department of Journal of Jilin Agricultural University, summarizes the application advantages of the system, discloses the problems in applying the system and puts forward some suggestions to provide references for the editorial departments and editorial staff who have not yet used or planned to use or recently began to use the manuscript management system.

\section{Composition and Functions of Manuscript Management System (Ver2.0)}

A manuscript management system refers to the realization of editing business processing platform for the collaboration of the five roles: authors, reviewers, the editorial board, editors in chief and editors; networking and the role making[8-9]. The manuscript management system was developed and designed by Beijing Magtech Science and Technology Development Co. Ltd. (Ver2.0)[10]. It 
consists of author submission system, expert review system, editorial board office system, chief editor review system and editorial office system. The system has the functions of online submission, online query, online review, remote editing, chief editor's decision, cost management, etc. A series of editing and publishing processes, such as submission, review and delivery can be completed and managed online $[8,11,12]$. This system is also the earliest manuscript management system used in China. The functions of the system are more complete. It has been used for relatively long time and it is more stable with more users. Therefore, it has become the preferred manuscript management system for many editorial departments [13].

\section{Application Advantages of Manuscript Management System}

Improving Work Efficiency and Shortening the Publishing Cycle. Traditional editing and publishing mode is that editors download the manuscripts from the e-mails and register papers one by one, which is a tedious and time-consuming job. However, the manuscript management system refers the work to authors, and they need to fill in the necessary information according to the cues when submitting manuscripts through the system. The system can produce the basic information of the manuscripts when the authors complete the submission, which is automatically recorded and stored in the database, the system registers the manuscripts while they are submitted, greatly improving the work efficiency. For the traditional publishing and editing mode, the manuscripts received need the "three trial", which involves more personnel, because of the asymmetry of information, it is very inconvenient for authors, reviewers and editors to communicate with each other, which makes the review cycle longer and the work intensity stronger. However, the manuscript management system provides a common platform for authors, editors and reviewers to solve the problems effectively. Through the system, the process of reviewing manuscripts can be sped up and the cycle of reviewing manuscripts can be shortened. The chief editor may distribute the reviewed manuscripts to every editor in time and grasp the distribution of manuscripts in real-time progress and how editors handle the manuscripts assigned to them. On the condition that the network is not blocked, the communication between authors, reviewers, the editorial board, editors in chief and editors can be carried out online anytime and anywhere. Whether the manuscripts are from experts or ordinary authors, the manuscript information can be more timely and accurately fed back. As long as the information can be updated in time, authors can find the processing of the manuscripts in real time. In addition, the application of the manuscript management system will attract excellent manuscripts both at home and abroad, and increase the resources of journal manuscripts $[9,13,14]$. Practice has proved that the system can transfer the real-time information between authors, reviewers, the editorial board, chief editors, editors and readers, lighten the burden of editing, greatly improve work efficiency, shorten journal publishing cycle, enhance the timeliness of information and realize the journal publishing digitization, networking and modernization. At the same time, it facilitates the authors' delivery, modification and query of the manuscripts, and improves the authors' satisfaction, which can attract more high-quality manuscripts, thus improving the quality of journals.

Standardizing Process and Avoiding Manuscript Loss. The traditional editing and publishing process is that authors submit manuscripts freely or editors ask for manuscripts, editors register all the manuscripts, then chief editors distribute manuscripts to editors in charge, who have the first trial and the manuscripts passed by the first trial directly go to the external trial. The editors in charge contact authors whose manuscripts shall be revised. The manuscripts shall be reviewed after revising and the review shall be conducted by experts or senior editors. Editors in charge inform the authors whose manuscripts are rejected. The manuscripts passed by the external trial shall be edited directly for final approval. Final manuscripts are edited and proofread by editors in charge, followed by publishing, typesetting, printing and distribution. The whole process of reaching the final manuscripts is complicated, especially in the review stage, involving more personnel. However, the manuscript management system can realize the management of the whole process from the submission to the review and facilitate the chief editors making arrangements and routine management[7]. At the same time, the public platform provided by the system can make manuscript 
information and editing workload counted more convenient[13]. The manuscript management system can set up the work flow according to the actual need of the editorial departments. It can also regulate the working procedures of the editorial staff and try to avoid the subjective factors of the editors affecting the progress and quality of work $[13,14]$. In addition, the application of the manuscript management system can effectively avoid the loss of manuscripts. Before the use of manuscript management system, the editorial department of the Journal of Jilin Agricultural University mainly uses e-mail (mainly) and post office (supple mentally) ways to communicate with experts and authors. It is easy to make the manuscripts lost by the way of postage. Although e-mails have improved office efficiency compared with the traditional mail, it also has some problems, for example, some messages are rejected by defaulting as junk mails and some mails will be unable to display or can't be read regularly because of system formatting problems, thus delaying editing. However, after the application of the manuscript management system, authors can submit manuscripts on line, experts can review online, effectively avoiding the loss of manuscripts [7, 14].

Promoting Academic Exchanges and Enhancing Journal Influence. At present, more editorial department websites are using the second-level domain names, authors and readers can not directly search information in the search engine but with the assistant of the manuscript management system, they can apply for the first-level domain names so that it is easier for them to find the editorial department websites to understand the relevant information. In addition, most of the electronic versions of the papers of the current academic journals are published by CNKI, Wan Fang, and VIP databases, but these databases are need to be paid to download, many readers cannot read the whole papers for free at any time through the Internet. However, the manuscript management system can make the editorial departments publish the whole papers so that readers can download the papers they need for free by browsing the websites of the editorial departments, which increases the reading quantity of the publications so as to promote academic exchange and enhance the influence of the journals[7,13,14].

\section{The Common Problems and Suggestions in Application of Manuscript Management System}

There are some common problems in application of the system: Some editors are old-fashioned in their ideas, affecting the use of the system; some editors are not skilled in operating the system, affecting work efficiency; the submission interface is not reasonable, affecting the authors' submission; review interface is too complex, affecting expert review; manuscript quality review system is not perfect, affecting the quality of manuscripts; the system maintenance is not timely, affecting the normal operation of the system. As for the problems mentioned above, some suggestions are put forward.

Editors Should Change Their Ideas and Accept the Application of the System. The traditional editing and publishing model is deeply rooted in editors for a long time. While the application of the manuscript management system brings convenience to editing and publishing, it will inevitably bring some impact to the traditional editing and publishing model. In order to make better use of the system, the editorial department needs to make a rational division of labor, overall arrangement of personnel and their specific work according to the change in the mode of work. Therefore, editors need to update awareness and change their ideas, only in this way can the functions of the system be brought into full play and work efficiency can be improved [13]. This requires editors to take part in related training so that they can get familiar with and master the functions and application of the system as soon as possible.

Being Skilled in Operating the System and Improving the Work Efficiency of Editors. Network of editing process is a guarantee to improve the quality of editing. The application of manuscript management system improves the efficiency of editing work and realizes the process of editing work without paper. In the early days of using the new system, the application of the system is sometimes affected by the hardware environment, the software environment and the lack of computer skills, which requires editors to be more skilled in operating the system , carry on the repeated practice of the multiple processes to handle the manuscripts, discover the problems appearing in the process of the system in time, analyze and solve the problems, thereby shortening 
the friction period of using the system and improving work efficiency. In addition, editing and proofreading is an important part of quality standardization of papers in the whole process of publication and this work is mechanical, tedious and time-consuming and takes up a lot of editing time. If we can integrate the functions of the editing and proofreading in the manuscript management system, it will bring great convenience to the publishing work [7, 13, 14].

Optimizing Procedures of the Authors' Submission and Ensuring the Submission Channel Smooth. One of the important tasks of the editorial departments is to facilitate the author's submission. However, the manuscript management system is mainly developed from the professional perspective, the design of the interface is too professional so that it is too complex for the authors to operate the interface and more icons and symbols are used on the interface which results in the authors' difficult understanding in the process of submission. Therefore, the manuscript upload is unsuccessful and the information is not sent smoothly, which leads to the loss of high-quality papers. In addition, some authors also make submission of one manuscript to several journals for the sake of time. Therefore, the editorial departments should further adjust and optimize the author's online submission, check manuscripts, modify the information and other procedures [14].

Simplifying the Interface of Expert Review and Improving the Efficiency of Review. Expert review is an important link to speed up the progress of manuscript processing and directly affects the processing cycle of manuscripts. In the establishment of the expert bank, editors should pay attention to the age of experts, professional structure, unit and so on. Some older reviewers have some difficulties in network review, which sometimes leads to delaying in review. Therefore, in the design of review interface, we should further simplify operating procedures for the convenience of the older experts. The icons and texts displayed on the expert review interface should be as concise and clear as possible [14].

Improving the Manuscript Evaluation Work and Increasing the Quality of Manuscripts. The existing manuscript management system pays more attention to the process management for manuscript review, focusing on the automation and network management of submission, reception and review etc. to speed up and save time for reviewing and management costs, but the service for increasing the quality of the editing is relatively insufficient. In recent years, domestic research and development staff of the manuscript management system pay more attention to the development of intelligent quality evaluation and have introduced academic misconduct testing system and reference proofreading system etc. [7, 13, 14]. Practice has proved that applying these supporting systems brings convenience to the editorial work of editors to a certain extent, not only improves work efficiency, but also ensures the quality of manuscript sources.

Maintaining the System Regularly and Ensuring Data Security. All the functions of the manuscript management system are backed by database resources in the background and the biggest hidden danger of the resources is security. Once the database is destroyed, all electronic resources will be lost. The staff is assigned different roles under the manuscript management system, including authors, reviewers, the editorial board, editors in chief and editors. Different roles log in different interfaces when they enter the system. Editorial personnel should enter the system from the editing entry. At present, the domestic manuscript management system stores data by a server backup. Although the existing editing system has more perfect security mechanism, the system maintenance personnel are regularly required to perform proper maintenance. This requires the editorial staff who $\log$ in the system regularly clean up useless data, backup important data, maintain their own computers, pay attention to anti-virus so as not to affect the normal work of the system $[9,13]$.

\section{References}

[1] Y.B. Xu, Z.Q. Yang and Y.Z. Song: Some suggestions on online submission system of sci-tech periodicals[J].Acta Editologica, Vol.22 (2010) No.3, p.260-261.(in Chinese).

[2] X.L. Zhang andW. Wen: Practice and perspectives of online manuscript management system:application in united editorial office for journals[J].Acta Editologica, Vol.24 (2012) 
No.3 p.272-273.(in Chinese).

[3] J.Wei andL.Wang: Application Experience of Manuscript Management System[J]. TODAY'S MASSMEDIA, (2012) No.6 p.104-105.(in Chinese).

[4] X.Huang, R.Qi, H.ShuiandX.W.Xu: Analysis of operation of a manuscript management system[J]. Acta Editologica, Vol.20 (2008) No. 2 p.153-154.(in Chinese).

[5] J.X.Zeng, M.N.Zhang and H.Y. Qu: Construction strategy of database of high quality scientific journals[J]. Acta Editologica, Vol.18 (2006) No.2 p. 87-89.(in Chinese).

[6] X.M. Jing and T.F.Yuan: Application of Manuscript Management System in Manuscript Processing and Management of Sci-tech Journals[J]. STUDY of EDITOL SCI-TECH, (2005) No. 4 p. 4-9. (in Chinese).

[7] S.H.Zhang, Q.Xu and H.M. Wang: Advantages and Current Situation of Manuscript Management System[J].Hunan Journal of Traditional Chinese Medicine, Vol. 32 (2016) No.7 p. 211-212. (in Chinese).

[8] A. D.Li: Establishment of Periodical Network Manuscript Management System[J].Metallurgical Information Review, (2006) No. 5 p. 46-47. (in Chinese).

[9] Y. Yang: Research on the Sci-tech Periodicals Network Purchasing \&Cataloging System[J]. Information Science, Vol.29 (2011) No.6 p. 864-866.(in Chinese).

[10] Manuscript Management System Manual. Beijing Magtech Science and Technology Development Co. Ltd.[EB/OL].http://www.magtech.com.cn,2011-03-27.(in Chinese).

[11] Q. Yang and X.L. Liu: Features of manuscript editing systems both at home and abroad[J].Journal of Chang'an University(Social Science Edition), Vol. 17 (2015) No. 2 p. 99-103.(in Chinese).

[12] Q.J. Miao: Application of Remote Manuscript Management System ofSci-tech Journals[J]. Acta Editologica, Vol.19 (2007) (Sup.) p. 49-50. (in Chinese).

[13] T. Zeng: Current Situation and Prospect of Manuscript Management System[J]. Jianghan Univ. (Nat.Sci. Ed), Vol.40 (2012) No.4 p. 101-104.(in Chinese).

[14] W.W. Zhang, W.J. Yang, C.M. Fu and D.H. Shi: Application of Manuscript Management System [J].Education of Chinese Medicine, Vol. 31 (2012) No. 5 p. 76-77.(in Chinese). 